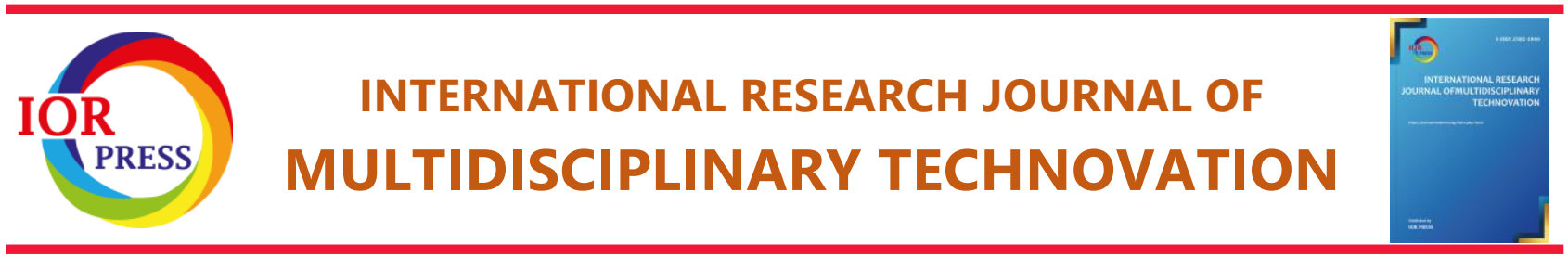

\title{
Traffic Controller for Vip/Ambulance Vehicle \& Location Tracking
}

\author{
V. Karthik ${ }^{1,}{ }^{*}$, K. Manoj Balaji ${ }^{1}$, M. Manoj Kumar ${ }^{1}$, N. Manoj Kumar ${ }^{1}$, \\ M. Naren Kumar ${ }^{1}$
}

${ }^{1}$ Department of Electronics and Communication Engineering, Sri Krishna College of Engineering and Technology, Coimbatore641008, Tamil Nadu, India.

* Corresponding author Mail :karthik@skcet.ac.in

DOI: https://doi.org/10.34256/irjmt2112

Received: 03-12-2020, Revised: 11-01-2021, Accepted: 15-01-2021, Published: 28-01-2021

Abstract: In India the rate of inhabitants is increased day By day but as compare to other countries India is having a poor Road transportation system. So due to these the Emergency Vehicles like mobile hospital, Fire service vehicle, VIP Vehicle, and police vehicle. Vehicle always faced so many problems to reach the destination. If an Ambulance stuck in a traffic then the patient inside it can Lose his/her life. Indians now a days gets aware about organs contributions, the rate of organ donation is also increased. But the main problem in organ transport is that it remains healthy only for very short time. So transporting them is a time dependent task. If the Emergency Vehicles do not reach at its destination point in time it causes human health and wealth. So by using a process that clearing the traffic signal before an Emergency Vehicle Reaches to the signal using IOT will resolve the problem.

Keywords: Raspberry pi, GPS, LED’s, RF Module.

\section{Introduction}

India is a second most Congested country with the growing wealth. In India, the roadway congestion is the main problem. Vehicles are more, and the rate of architecture is slow, due to cost constraints and space. Indian traffic system is disarranging and non-lane based, so it must require a way by which we can solve the problem [1]. Brainy administration of traffic flows is to be used to avoid the traffic crowding. Extremity vehicles in various countries would not have their own access to roads. Which results rescue squad are gets blocked from reaching their end point. Moreover, when lights flash and horn are on, drivers at crossing are must give a path to emergency vehicles. Unfortunately, many upset drivers do not. "With all the horns, whistles, lights on the ambulance, still not everyone gives a path to us," says rescuer from the Urgent Medical Services quoted in the unit [2]. The one thing that certainly still attracts everyone's attention is a red traffic signal. Even though people want to give a way to the mobile hospital, traffic conditions might prevent them to give a way to the mobile-hospital [3]. Using an Brillant administration designed for hospital wagon will allow the mobile hospital to move faster and to reach its destination in proper time [4].

\section{Ease of Use}

In today's world traffic congestions plays one of the major role in the road. There's lots of probabilities of occurring accidents in the road, to carry a accident person he/she must carry to hospital on time. if it fails there will be lose of a life. The most reason for the loss of lives happens is only reason is the Traffic [5].

\section{Description}

\section{Overview}

Traffic controller works on mechanically sight (Switch controlled). When Switch control hits on the specific lane, On the specific lane traffic signal has receiving unit by detecting its frequency range, it hits Green signal, rest of the signal will get Red signal. By this method traffic can clear, can get rid from the avoiding traffic [6].

\section{Description}

The proposal deals with a system that mechanically sight, when the device detects the frequency range [7]. Raspberry $\mathrm{Pi}$ acts because the heart of our system. Once it detects the frequency it starts to have a control on it, so we can change the traffic 
signal from red to green by switching controller which is fixed inside the ambulance/VIP. modules.

The project is sub-divided into 3 totally different

They are,

- Frequency Detection

- Controlling

- Location

\section{Connected Works}

\section{Traffic Clearance System for Life Saving Vehicle}

There are many method in clearing the path of the crisis vehicles. Methods of emergency passage have been proposed using GPS and Bluetooth [5]. In general, the crisis vehicle path clearance method involves in using a pre-established announcement module installed in the ambulance, which informs the people on the roadway about the arrival of an ambulance in an crisis. But what actually matters is the ease of use and the profitable cost in implementing the design. In while using a GPS part, the lucrative cost is too high that it can't be installed in all vehicles [3].

\section{Intelligent Traffic Control System for Ambulance}

In Green Passage system was discussed, which was used to provide permission to any extremity vehicle by turning all the red lights to green on the path of the plight vehicle, hence providing a complete green passage to the desired vehicle. A green corridor is the sync of the green phase of the traffic signals [2]. With a green passage way setup, a vehicle passing through a green signal will resume to receive green signals as it travels down the road.

In supplementary to the green corridor path, the system will track a crisis vehicle like ambulance and VIP vehicle when passes through a traffic light. Superiority of the system is that GPS inside vehicle does not require additional power [5]. The biggest drawback of green corridor is that, when the wave is disturbed, the disturbance can cause traffic problem that can be exacerbated by the synchronization.

In such cases, the line of vehicles in a green pathway grows in size until it becomes too large and some of the vehicles cannot reach the green lights in time and must stop [8]. The quick-witted congestion control system using RFID and Cloud uses an android application, use of RFID (Radio Frequency Identification) and also cloud. The main disadvantage of this project is the use of RFID, because the range of RFID is very limited and can't be detected soon.
Whereas in our project we are using image processing which does not require any range. This project focuses more on traffic congestion. The smart traffic control system using image processing uses image processing for traffic congestion control [6]. This project also mainly focuses on traffic crowd. The image processing based adaptive crowd control system used image processing as well as artificial intelligence. The use of image processing as well as artificial intelligence will add consignment to the system [9].

\section{Proposed Module}

All the above-described proposals have nice potency over the ages. however all have minor disadvantages in it.

All these minor defects are taken into consideration and need to be overcome in our proposal. The traffic controller for ambulance/VIP's can detects the location, when it reaches it's certain frequency range. It additionally sends Associate in Nursing alert message with correct location to the nearby hospital.

One of the key benefits of our planned system is that alert message are going to be shared with correct location and it's not been introduced in any of those existing systems.

\section{Module Description \\ Frequency Detection}

This half is that the $1^{\text {st }}$ method of the traffic controller. During this section when the vehicle detects on the lane, Based on the frequency detection, it takes the control of the traffic signal [8]. And this detection method are going to be management by the most controller raspberry pi [7].

The Traffic controller device that detects the presence or movement of vehicle within the atmosphere. The device is Associate in the traffic signal that measures the surroundings and converts the knowledge into electronic data to record, monitor, or signal changes. RF sensors are commonly used in process engineering, military intelligence, chemical plants.

\section{Controlling}

When the Ambulance / VIP's vehicle are spotted in the traffic lane, it takes their control with the traffic signal, based on the traffic congestion, it can change into other command [10]. When the vehicle lost its frequency range, Automatically it comeback to their own signal position [4]. 


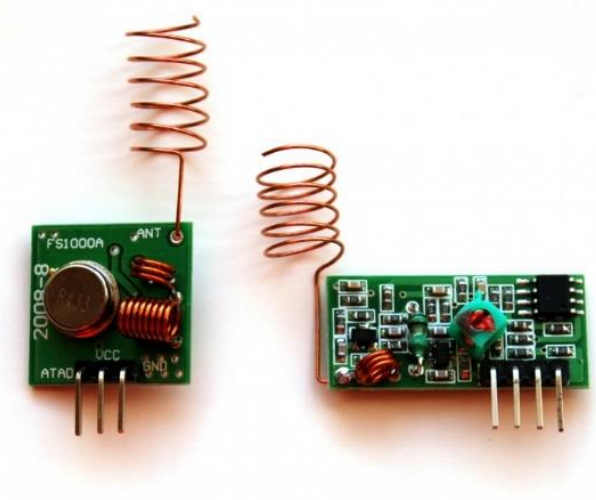

Figure 1. RF Module

\section{Location}

Location tracking device are fitted inside the Ambulance/ VIP's Vehicle, It runs only on 2-G because in a month, Normally it takes less than 30MB.It is totally enough to use the 2G Network [3]. The Global System for Mobile Communications (GSM) may be a commonplace developed by the eu Telecommunications Standards Institute (ETSI) to explain the protocols for second-generation (2G) digital cellular networks employed by mobile devices like mobile phones and tablets [5].

GSM is Associate in care open and digital cellular technology used for transmittal location services and knowledge services operate at the $850 \mathrm{MHz}, 900 \mathrm{MHz}$, $1800 \mathrm{MHz}$, and $1900 \mathrm{MHz}$ frequency band. GSM technology was developed as a digital system mistreatment the time division multiple access (TDMA) technique for communication functions [5].

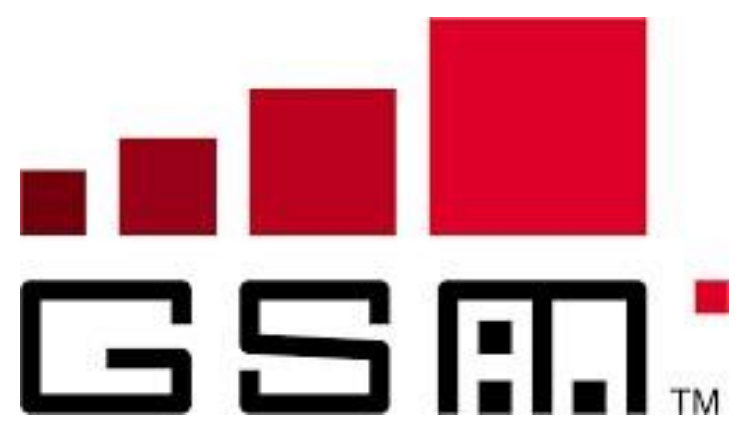

Figure 2.GSM

The main controller raspberry pi can operates the communication method through location once the is detected Associate in sends an alert message to the team of tracking surveillance or for the individuals who needs to monitor it [11-13].

This half plays the most role during this project it brings an efficient communication. By this effective communication between the traffic place and therefore the near by hospital/Station. The Vehicle will reach the destination place earl. It ends up in cut back the loss of lives on ambulance [5].

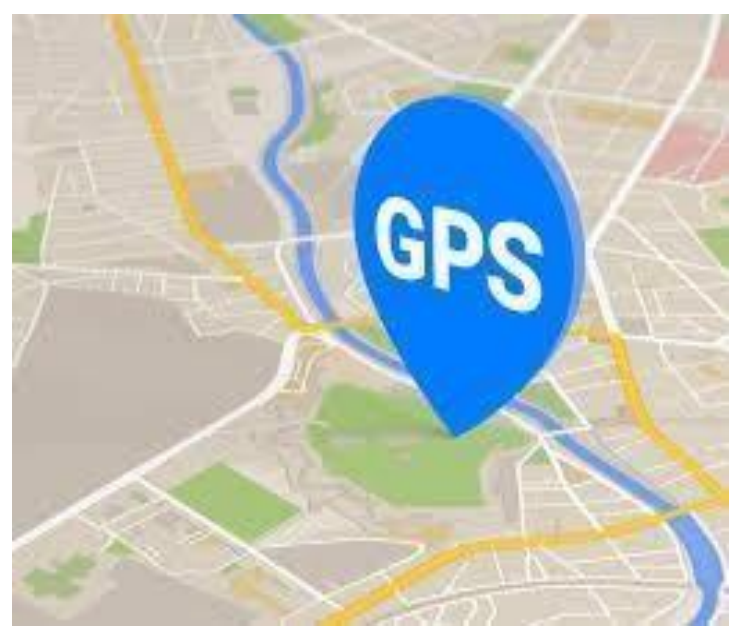

Figure 3. GPS

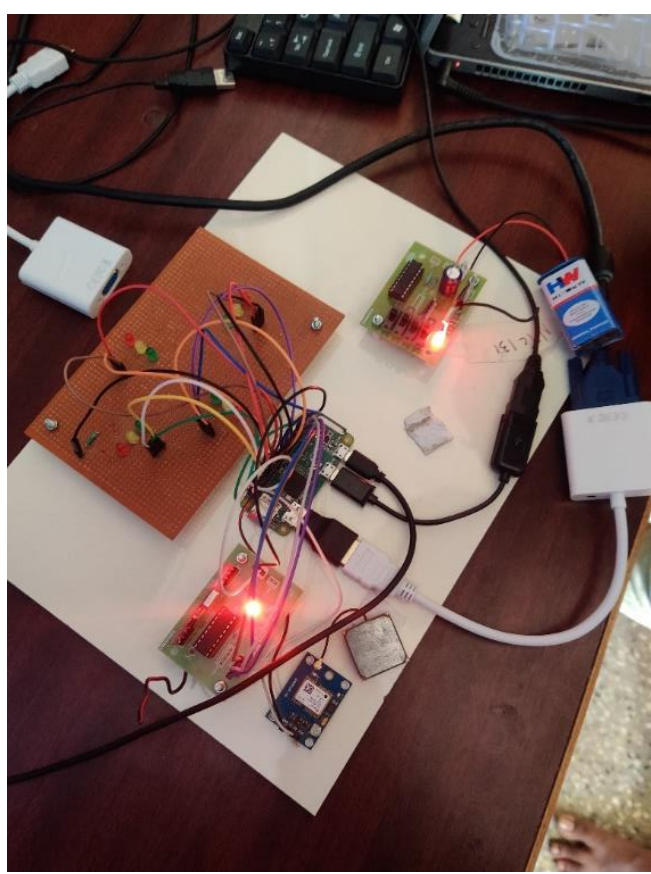

Figure 4. Real Model of Traffic Signal Unit

\section{Conclusion}

Using Pre-programmed traffic signal changes based on GPS system we can control the traffic. By this system, the traffic jam issue faced by the individuals can be reduced. Also in several condition where the crisis vehicles get fixed in a crowd such feverish situations can be avoided using this system. So in metropolis of countries like India, where the pavement is small and vehicles are more the impulsive traffic signal control system can become more useful.

\section{References}

[1] O. Sawade, I. Radusch, Survey and Classification of Cooperative Automated Driver 
Assistance Systems, 2015 IEEE 82nd Vehicular Technology Conference (VTC2015-Fall), Boston, MA, USA, (2015) 1-5 https://doi.org/10.1109/VTCFall.2015.7391161

[2] N. Al-Ostath, F. Selityn, Z. Al-Roudhan, M. ElAbd, Implementation of an emergency vehicle to traffic lights communication system, 2015 7th International Conference on New Technologies, Mobility and Security (NTMS), Paris, France, (2015) 1-5. https://doi.org/10.1109/NTMS.2015.7266494

[3] S. Sonika, K. Sathiyasekar, S. Jaishree, Intelligent accident identification system using GPS, GSM modem. International Journal of advanced research in computer and communication engineering, 3(2014) 54875489.

[4] R. Sundar, S. Hebbar, V. Golla, Implementing Intelligent Traffic Control System for Congestion Control, Ambulance Clearance, and Stolen Vehicle Detection, in IEEE Sensors Journal, 15(2015)

1109-1113

https://doi.org/10.1109/JSEN.2014.2360288

[5] N. Yuvaraj, V.B. Prakash, D. Venkatraj, Hi-Fi Traffic Clearance Technique for Life Saving Vehicles using Differential GPS System, International Journal of Computer and Information Engineering, 5(2011) 1157-1159.

[6] O. Sawade, B. Schäufele, I. Radusch, Collaboration over IEEE 802.11p to enable an intelligent traffic light function for emergency vehicles, 2016 International Conference on Computing, Networking and Communications (ICNC), Kauai, HI, USA, (2016) 1-5 https://doi.org/10.1109/ICCNC.2016.7440690

[7] F.A. Al-Nasser, H. Rowaihy, Simulation of dynamic traffic control system based on wireless sensor network. In 2011 IEEE Symposium on Computers \& Informatics (2011) 40-45.

[8] R. Hussin, R.C. Ismail, E. Murrali, A. Kamarudin, Wireless Traffic Light Controller for Emergency Vehicle through XBee and Basic Stamp Microcontroller, 41(2012) 636-642. Pages 568597https://doi.org/10.1016/j.proeng.2012.07.22 $\underline{3}$

[9] D.A. Balamurugan, G.N.S. Kumar, S.R. Thilak, P. Selvakumar, (2015) Automated Emergency System in Ambulance to Control Traffic Signals using IoT. Professor, Sri Krishna College of Technology, Coimbatore-42, Tamilnadu, India. Pages 540-556.
[10]

T. Chowdhury, S. Singh, S.M. Shaby, A Rescue System of an advanced ambulance using prioritized traffic switching. In 2015 International Conference on Innovations in Information, Embedded and Communication Systems (ICIIECS) (2015) 1-5.

[11] M.S. Iyyappan, M.V. Nandagopal, Automatic accident detection and ambulance rescue with intelligent traffic light system, International journal of advanced research in electrical, electronics and instrumentation engineering, 2(2013), 1319.

[12] S. Saranya, K. Rathinakumar, S. Maragatharaj, N. Saranya, A Novel Method of Ambulance Service Time Reduction Using Zigbee, International Journal of Advance Research in Science and Engineering, 2 (2013) 141.

[13] S.S. Riaz Ahamed, The Role of Zigbee Technology in Future Data Communication System, Journal of Theoretical and Applied Information Technology, 5(2009) 129-135.

\section{Acknowledgement}

This research was supported by our institute Sri Krishna College of Engineering and Technology. We are also grateful to our mentor Mr.V.Karthik, Assistant Professor, Department of ECE, SKCET for assisting us in moderating this paper in improving the manuscripts significantly. Also, we are thankful to our Head of the Department, Dr.S.Sophia who supported and corrected us in our technical vocabularies.

\section{Funding}

No funding was received for conducting this study.

\section{Conflict of interest}

The authors have no conflicts of interest to declare that they are relevant to the content of this article.

Author's contribution

All the authors equally contributed to this work.

About the License

(C) The author(s) 2021. The text of this article is open access and licensed under a Creative Commons Attribution 4.0 International License 